\title{
009 PP AN EVALUATION OF A PATIENT SAFETY COLLABORATIVE USING THE PARTICIPATORY RESEARCHER IN RESIDENCE MODEL
}

M Lalani, ${ }^{1 *}$ K Hall, ${ }^{2}$ P Toohey, ${ }^{2}$ M Skrypak, ${ }^{2}$ S Seaholme, ${ }^{2}$ C Laing, ${ }^{3}$ J Welch, ${ }^{4}$ L Eyre, ${ }^{1} \mathrm{M}$ Marshall ${ }^{1}$. ${ }^{1}$ Primary Care and Population Health, University College London, UK; ${ }^{2}$ UCL Partners, London, UK; ${ }^{3}$ The Royal Free London NHS Foundation Trust, UK; ${ }^{4}$ University College London Hospitals NHS Foundation Trust, UK

10.1136/bmjopen-2017-016492.27

Objective: To establish the motivating factors for member participation in a patient safety Breakthrough Series (BTS) Collaborative.

Design: A qualitative, process-oriented, formative evaluation using a participatory approach, the Researcher-in-Residence (RiR) model. The RiR embraces the concept of 'co-producing' knowledge between researchers and practitioners using qualitative research methods such as participant observation, interviews and documentary analysis. The design, creation and application of newly generated evidence is facilitated by the researcher through negotiation and compromise with team members.

Participants: Organisation directorate, doctors, nurses, programme managers and coordinators.

Setting: Two hospitals in South East England that are participating in the BTS and UCLPartners, the facilitator (core team) of the collaborative.

Results: The participatory nature of the evaluation has generated new knowledge such as identifying facilitators and barriers to motivation in 'real-time', thus enabling challenges to be addressed with team members as they arise. Initial emerging themes consider motivation in the context of individual, relational and organisational factors. At the individual level, incentives for participation focus on professional development. Relational factors centre upon the concept of learning and sharing across the collaborative network, which underpins the BTS approach and is enabled by UCLPartners as the core team. Organisational factors influencing motivation include resource capacity, quality improvement expertise, support and leadership. Conclusions: Participatory models of evaluation that embed researchers as part of an interdisciplinary healthcare delivery team may contribute to optimising the effectiveness of quality improvement approaches through collaboration. The co-creation of new transferable knowledge augments processes of change and may contribute to programme sustainability. 